\title{
Blood retention and antigenicity of polycarboxybetaine-modified liposomes
}

Taka-aki Ryujin ${ }^{1, \uparrow}$, Taro Shimizu $^{2, \uparrow}$, Ryo Miyahara ${ }^{1, \uparrow}$, Rena Shimazui ${ }^{1}$,Takuma Yoshikawa ${ }^{3}$, Akihiro

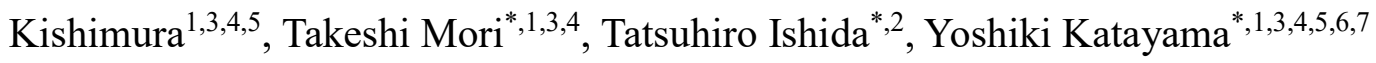

${ }^{1}$ Graduate School of Systems Life Sciences, Kyushu University, 744 Motooka, Nishi-ku, Fukuoka, 819-0395, Japan.

${ }^{2}$ Department of Pharmacokinetics and Biopharmaceutics, Institute of Biomedical Sciences, Tokushima University, 1-78-1 Sho-machi, Tokushima, 770-8505, Japan.

${ }^{3}$ Department of Applied Chemistry, Faculty of Engineering, Kyushu University, 744 Motooka, Nishi-ku, Fukuoka, 819-0395, Japan.

${ }^{4}$ Center for Future Chemistry, Kyushu University, 744 Motooka, Nishi-ku, Fukuoka, 819-0395, Japan.

${ }^{5}$ International Research Center for Molecular Systems, Kyushu University, 744 Motooka, Nishi-ku, Fukuoka, 819-0395, Japan.

${ }^{6}$ Centre for Advanced Medicine Innovation, Kyushu University, 3-1-1 Maidashi, Higashi-ku, Fukuoka, 8128582, Japan.

${ }^{7}$ Department of Biomedical Engineering, Chung Yuan Christian University, 200 Chung Pei Rd., Chung Li, 32023 ROC, Taiwan.

" These authors contributed equally to this work.

*Corresponding Authors: mori.takeshi.880@m.kyushu-u.ac.jp (T. Mori); ishida@tokushima-u.ac.jp (T. Ishida); ykatatcm@mail.cstm.kyushu-u.ac.jp (Y. Katayama). 


\begin{abstract}
Zwitterionic polycarboxybetaines (PCBs) have gained attention as alternative stealth polymers whose liposomal formulation and protein conjugates were reported not to elicit anti-polymer antibodies. Here, we studied the blood retention and antigenicity of liposomes modified with PCBs focusing on their chemical structures and doses. We compared PCBs with either 1 or 3 (PCB1 or PCB3) spacer carbons between the carboxylate and ammonium groups. PCB3-modified liposomes had a short blood retention, whereas PCB1modified liposomes demonstrated extended blood retention that was somewhat superior to PEGylated liposome. This confirmed the excellent non-fouling nature of PCB1 reported previously. Interestingly, PCB1-liposome as well as PCB3-liposome elicited specific IgMs toward each PCB. The dose-dependent production of specific IgMs to PCB-liposomes was similar to that of PEGylated liposome, i.e., high doses of PCB-liposomes reduced the production of specific IgMs, termed immunological tolerance. These results indicate the importance of investigating the effect of dose to clarify the existence of antigenicity of stealth polymers.
\end{abstract}

Keywords: polycarboxybetaine, zwitterionic polymer, liposome, antibody production, accelerated blood clearance phenomenon, blood retention 


\section{Introduction}

Polyethyleneglycol (PEG) is a stealth polymer with a non-fouling nature that avoids the non-specific adsorption of blood proteins. Therefore, PEGylation has been applied to nanocarriers and therapeutic biomolecules to extend their blood half-life. Despite the non-fouling nature of PEG, accumulating evidence has suggested that the administration of PEGylated nanocarriers and biomolecules induce the production of antiPEG antibodies in humans and animals, which results in the accelerated blood clearance (ABC) of these PEGylated therapeutics.[1][2][3] Among PEGylated therapeutics, liposomes have been studied extensively to investigate the influence of various factors such as the molecular parameters of PEGylated liposomes and their administration schedule. PEGylated liposomes induce the production of anti-PEG IgMs in various animals.[4][5] In mice, anti-PEG IgMs are mainly produced by splenic marginal zone B cells via a T cellindependent mechanism.[6] High doses of PEGylated liposomes induced immunological tolerance in which the induction of anti-PEG IgM was markedly suppressed. [4] [7]

Recently, it was reported that the number of humans harboring natural anti-PEG antibodies is increasing rapidly.[2][8] Because the generation of anti-PEG antibodies abrogates the efficacy of PEGylated therapeutics, the development of alternative stealth polymers that do not induce anti-polymer antibodies is anticipated. Zwitterionic polymers such as polycarboxybetaines (PCBs) (Figure 1) and polytrimethylamine Noxide are considered alternative stealth polymers because liposomes[9] and protein conjugates[10][11][12] modified with these polymers were reported not to induce anti-polymer antibodies. In PCBs, carbon spacer length between ammonium and carboxylate determines their non-fouling nature. PCBs with a spacer length $\mathrm{m}$ $=1$ or 2 showed an excellent non-fouling nature, while those with $\mathrm{m} \geq 3$ had a reduced non-fouling nature.[13][14] The critical effect of the spacer length on the non-fouling nature of PCBs was attributed to lower charged zwitterionic groups with $\mathrm{m} \leq 2$ related to the interplay between the positive and negative charges[15], which were speculated to have weak interactions with proteins [16]. Therefore, PCBs with $\mathrm{m} \leq 2$ were used to examine PCB antigenicity in previous studies.[9] [10][11]

In the present study, we investigated the effect of the carbon spacer length of acrylamide-type PCBs on the stealthness of PCB-modified liposomes. We also examined the effect of dose on the antigenicity of the PCB-modified liposomes because our previous research indicated the dose of PEGylated liposomes critically affected the production of anti-PEG IgM, which were diminished at high doses. [4] [7]

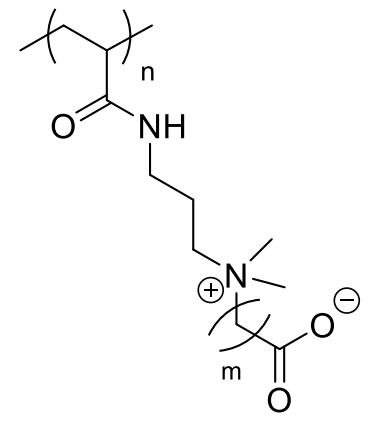

acrylamide-type

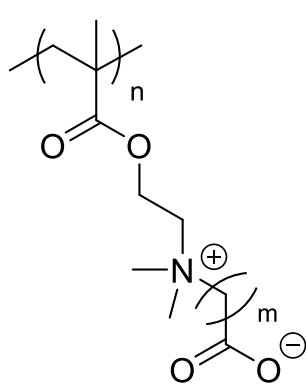

methacrylate-type 
Figure 1. Chemical structures of the two types of PCBs reported to date. Acrylamide-type PCBs were used in this study.

\section{Experimental Section}

\section{Materials}

Hydrogenated egg phosphatidylcholine (HEPC), 1,2-distearoyl-sn-glycero-3-phosphoethanolamine- $n$-methoxy (polyethylene glycol)-2000] ( $\mathrm{mPEG}_{2000}-\mathrm{DSPE}$ ), and 1,2-distearoyl-sn-glycero-3-phosphoethanolamine (DSPE) were purchased from NOF (Tokyo, Japan). Cholesterol (Chol) was of analytical grade (FUJIFILM Wako Pure Chemical Co., Osaka, Japan). All lipids were used without further purification. All other reagents and solvents were purchased from Sigma-Aldrich, Tokyo Chemical Industry, or FUJIFILM Wako Pure Chemical Co., and were used as received unless otherwise noted.

\section{Animals}

BALB/c male mice, 5 weeks old, were purchased from Japan SLC (Shizuoka, Japan). All animal experiments were evaluated and approved by the Animal and Ethics Review Committee of Tokushima University.

\section{Synthesis of 2a}

1a was synthesized according to the literature.[11] 4-Cyano-4[(dodecylsulfanylthiocarbonyl)sulfanyl]pentanoic acid (CDP, $108 \mathrm{mg}, 0.27 \mathrm{mmol}, 1 \mathrm{eq}), \mathbf{1 a}(2.0 \mathrm{~g}, 5.76 \mathrm{mmol}$, $21 \mathrm{eq}$ ), V-501 (initiator, $8.9 \mathrm{mg}, 0.054 \mathrm{mmol}, 0.2 \mathrm{eq}$ ) were firstly dissolved in anhydrous dimethylformamide (DMF, $8 \mathrm{~mL}$ ) in a $25 \mathrm{~mL}$ pear shaped flask. The flask was sealed with a rubber septum and bubbled with $\mathrm{N}_{2}$ for $30 \mathrm{~min}$, then transfer to an oil bath $\left(70^{\circ} \mathrm{C}\right)$ for $4 \mathrm{~h}$. The resultant polymer (2a) was precipitated in ice-cold ethyl acetate three times and dried under vacuum. Yellowish solid. ${ }^{1} \mathrm{H}$ NMR (300 MHz, $\left.\mathrm{CDCl}_{3}\right) \delta(\mathrm{ppm}): 0.85-0.89$, 1.2-1.3, 1.3-1.9, 2.0-2.4, 3.1-3.4, 3.4-3.7, 3.7-4.1, 4.4-4.8. Degree of polymerization was determined from an area ratio of two peaks (0.85-0.89 and 4.4-4.8) in ${ }^{1} \mathrm{H}$ NMR (Figure S1) and calculated to be $\mathrm{n}=24$.

\section{Synthesis of 3a}

Triethylamine (TEA, $280 \mu \mathrm{L}, 2.009 \mathrm{mmol}, 10 \mathrm{eq})$, hexylamine $(264 \mu \mathrm{L}, 1.998 \mathrm{mmol}, 10 \mathrm{eq})$ and tris(2carboxyethyl)phosphine hydrochloride (TCEP, $86.2 \mathrm{mg}, 0.301 \mathrm{mmol}, 1.5 \mathrm{eq}$ ) were dissolved in anhydrous DMF $(4 \mathrm{~mL})$ to remove the trithiocarbonate group from $1000 \mathrm{mg}$ of $\mathbf{2 a}$. After being stirred at RT for $5 \mathrm{~h}$, the color of reaction solution turned into colorless. Then, the product (3a) was precipitated in ice-cold ethyl acetate and dried under vacuum to obtain a white powder. Yield: $94 \%$. ${ }^{1} \mathrm{H}$ NMR $\left(300 \mathrm{MHz}, \mathrm{CDCl}_{3}\right) \delta(\mathrm{ppm}): 1.4-1.6,1.5-$ $1.9,1.9-2.4,3.1-3.4,3.5-4.0,4,0-4.2$.

\section{Synthesis of $4 a$}

3a $(0.0285 \mathrm{mmol}$, 1eq.) was first converted into an anhydride by the reaction in $5 \mathrm{~mL}$ chloroform with $1 \mathrm{H}-$ benzotriazol-1-yloxy-tri(pyrrolidino)phosphonium hexafluorophosphate (PyBOP, $22 \mathrm{mg}, 0.042 \mathrm{mmol}, 1.5 \mathrm{eq}$.) 
for $4 \mathrm{~h}$ at room temperature. A solution of DSPE $(22.4 \mathrm{mg}, 0.03 \mathrm{mmol}, 1 \mathrm{eq}$.) in $1 \mathrm{ml}$ chloroform and $\mathrm{N}, \mathrm{N}$ diisopropylethylamine (DIEA, $10 \mu \mathrm{L}, 0.057 \mathrm{mmol}, 2$ eq.) was then added to the 3a/PyBOP solution and the mixture was stirred for 4 days at $40{ }^{\circ} \mathrm{C}$. Then, the product (4a) was precipitated in ice-cold ethyl acetate and dried under vacuum to obtain a white powder. Yield: $33 \%$. ${ }^{1} \mathrm{H}$ NMR $\left(300 \mathrm{MHz}, \mathrm{CD}_{3} \mathrm{OD}\right) \delta(\mathrm{ppm}): 0.85-0.91$, $1.28-1.35,1.4-1.6,2.0-2.4,3.1-3.4,3.5-3.7,4.1-4.3$.

\section{Synthesis of 5 a}

5a was obtained after $4 \mathrm{~h}$ of acid deprotection (TFA, $\sim 2 \mathrm{~mL}$ per $1 \mathrm{~g}$ polymer, $\sim 10$ eq.) followed by a dialysislyophilization step. White powder. Yield: $23 \% .{ }^{1} \mathrm{H}$ NMR (300 MHz, $\left.\mathrm{D}_{2} \mathrm{O}\right) \delta(\mathrm{ppm})$ : 0.7-0.8, 1.0-1.3, 1.3-1.8, $1.8-2.3,3.0-3.3,3.4-3.6,3.7-3.9$.

\section{Synthesis of $\mathbf{2 b}$}

$\mathbf{1 b}$ was synthesized according to the literature.[11] $\mathbf{2 b}$ was synthesized similarly to $\mathbf{2 a}$. Viscus yellowish liquid. ${ }^{1} \mathrm{H}$ NMR (300 MHz, $\mathrm{CDCl}_{3}$ ) $\delta$ (ppm): 0.85-0.89, 1.23-1.31, 1.3-1.5, 1.5-1.9, 1.9-2.1, 2.1-2.4, 2.4-2.5, 2.9-3.1, 3.1-3.5, 3.5-3.7, 3.7-3.9. Degree of polymerization was determined from an area ratio of two peaks (0.85-0.89 and 2.4-2.5) in ${ }^{1} \mathrm{HNMR}$ (Figure S2) and calculated to be $\mathrm{n}=22$.

\section{Synthesis of $\mathbf{3 b}$}

3b was synthesized similarly to 3a. White powder. Yield: $92 \% .{ }^{1} \mathrm{H}$ NMR $\left(300 \mathrm{MHz}, \mathrm{CDCl}_{3}\right) \delta(\mathrm{ppm})$ : 1.35-1.5, $1.5-1.9,1.9-2.3,2.3-2.5,3.1-3.5,3.5-3.7,3.7-3.9$.

\section{Synthesis of $4 b$}

4b was synthesized similarly to 4a. White powder. Yield: $29 \%$. ${ }^{1} \mathrm{H}$ NMR (300 MHz, $\left.\mathrm{CD}_{3} \mathrm{OD}\right) \delta$ (ppm): 0.85 $0.89,1.12-1.28,1.33-1.51,1.5-1.9,1.6-2.1,2.1-2.4,2.7-2.9,2.9-3.1,3.1-3.4$.

\section{Synthesis of $\mathbf{5 b}$}

5b was synthesized similarly to 5a. White powder. Yield: $21 \%$. ${ }^{1} \mathrm{H}$ NMR $\left(300 \mathrm{MHz}, \mathrm{D}_{2} \mathrm{O}\right) \delta(\mathrm{ppm}): 0.7-0.8$, 1.15-1.2, 1.2-1.7, 1.7-2.0, 2.1-2.4, 2.8-2.9, 2.9-3.1, 3.1-3.4.

\section{Preparation of PCB-modified liposome}

The lipid composition of the prepared liposome is HEPC/Chol/polymer-lipid =2-X: 1 : X (molar ratio, $\mathrm{X}=0.15$, $0.30,0.45)$. At the time of pharmacokinetic analysis, the fluorescent dye DiI was added at $1 \mathrm{~mol} \%$ to the phospholipid. Liposomes were prepared by the Bangham method. First, each lipid was dissolved in an organic solvent and added to a test tube, and then the solvent was removed by an evaporator to form a lipid film. After leaving overnight with a vacuum pump, HEPES-buffered saline (HBS) was added and incubated at $65{ }^{\circ} \mathrm{C}$ for 1 $\mathrm{h}$ to hydrate the lipid film. Subsequently, the liposome was passed through a polycarbonate filter with $400 \mathrm{~nm}$, $200 \mathrm{~nm}, 100 \mathrm{~nm}$, and $80 \mathrm{~nm}$ using an extruder to adjust the particle diameter to about $100 \mathrm{~nm}$. The particle size and $\zeta$-potential of the prepared liposomes were measured by a dynamic light scattering method (ZETASIZER 
NANO, Malvern). The liposome concentration was measured by a phosphate assay.

\section{Pharmacokinetic evaluation after single administration of PCB-modified liposome}

Various PCB-modified liposomes labeled with DiI were intravenously administered to BALB/c mice [5 $\mu$ mol phospholipids (PL)/kg]. As a control, PEG-modified liposomes (PEG density 5\%) were intravenously administered. Blood was collected from the tail vein 1, 4, 8, $24 \mathrm{~h}$ after administration, and then centrifuged to collect serum. The amount of DiI-labeled liposomes in the serum was measured with a fluorescent plate reader (Excitation: $535 \mathrm{~nm}$, Emission: $590 \mathrm{~nm}$ ). After $24 \mathrm{~h}$, the liver was collected, embedded in OCT compound, and frozen. Frozen sections ( $7 \mu \mathrm{m}$ ) were prepared using a cryostat (Leica CM1860), and accumulation of liposomes in the liver was observed with a fluorescence microscope (BZ-9000, KEYENCE).

\section{Evaluation of antibody induction by administration of PCB-modified liposome}

PCB-modified liposomes (PCB density 10\%) were intravenously administered to BALB/c mice at various doses $(0.001,0.01,0.1,1,10 \mu \mathrm{mol} \mathrm{PL} / \mathrm{kg}$ ). As a control, PEG-modified liposome (PEG density 5\%) was intravenously administered $(0.01 \mu \mathrm{mol} \mathrm{PL} / \mathrm{kg})$. On days 3, 5, 7, and 14 after administration, blood was collected from the tail vein, and then centrifuged to collect serum. The amount of anti-polymer antibody in the serum was measured by enzyme-linked immunosorbent assay (ELISA) shown below.

\section{ELISA}

Various liposomes were added to a 96-well plate (Costar, Corning) $(0.1 \mu \mathrm{mol} \mathrm{PL} / \mathrm{mL})$ and incubated at room temperature for $2 \mathrm{~h}$. After removing the liposome solution, 1\% BSA was added to perform blocking at room temperature for $1 \mathrm{~h}$. After washing 3 times, diluted serum was added and incubated at room temperature for 1 h. After washing 5 times, HRP-labeled anti-mouse IgM (MILLIPORE) or HRP-labeled anti-mouse IgG (BETHYL) was added, and the mixture was further incubated for $1 \mathrm{~h}$. After washing five times, $1 \mathrm{mg} / \mathrm{mL}$ ophenylene diamine (Sigma) was added to perform a color reaction. The reaction was stopped using $2 \mathrm{M}$ sulfuric acid, and the absorbance at $492 \mathrm{~nm}$ was measured with a plate reader.

\section{Pharmacokinetic evaluation of repeated administration of PCB-modified liposomes}

PCB-modified liposomes (PCB density 10\%) were intravenously administered to BALB/c mice $(0.1 \mu$ mol $\mathrm{PL} / \mathrm{kg}$ ). As a control, PEG-modified liposome (PEG density 5\%) was intravenously administered (0.01 $\mu \mathrm{mol}$ $\mathrm{PL} / \mathrm{kg}$ ). Five days after the administration, various DiI-labeled liposomes were intravenously administered (5 $\mu \mathrm{mol} \mathrm{PL} / \mathrm{kg}$ ). Four hours after the administration, blood and liver were collected, and the liposome concentration in serum and the accumulation of liposome in the liver were evaluated in the same manner as in the previous section.

\section{In vitro antibody induction evaluation}

Spleen was collected from the BALB/c mouse, and a spleen cell suspension was prepared. Spleen cells and various liposomes were added to a 24 -well plate and cultured at $37{ }^{\circ} \mathrm{C}$ in a $\mathrm{CO}_{2}$ incubator (final concentration: 
$5 \times 10^{6}$ cells $\left./ \mathrm{mL}, 1 \mathrm{pmol} \mathrm{PL} / \mathrm{mL}\right)$. Five days later, the culture supernatant was collected, and the amount of the antibody in the culture supernatant was measured by ELISA described above.

\section{Results}

\section{Synthesis of lipid-modified PCBs and liposome preparation}

Lipid-modified PCBs were synthesized following Scheme 1 based on a previous study.[11] PCBs were obtained by reversible addition-fragmentation chain transfer polymerization. The degree of polymerization was 24 and 22 for PCB1 and PCB3, respectively, equivalent to that of PCB2, which did not induce anti-polymer antibodies when liposome modified.[9] After removing the trithiocarbonate group, a thiol group appeared on the terminus of the PCBs. The terminal thiol group might enhance the antigenicity of PCBs [17] and this effect is discussed later. We prepared liposomes with different PCB content $(5,10$, and $15 \mathrm{~mol} \%$ in total lipids) and their characteristics are summarized in Table 1. The sizes of the liposomes were in the range of $80-110 \mathrm{~nm}$. Absolute values of the $\zeta$-potential of PCB-liposomes were equivalent to PEG-liposome prepared as a control, with a neutral surface charge related to their zwitterionic nature.
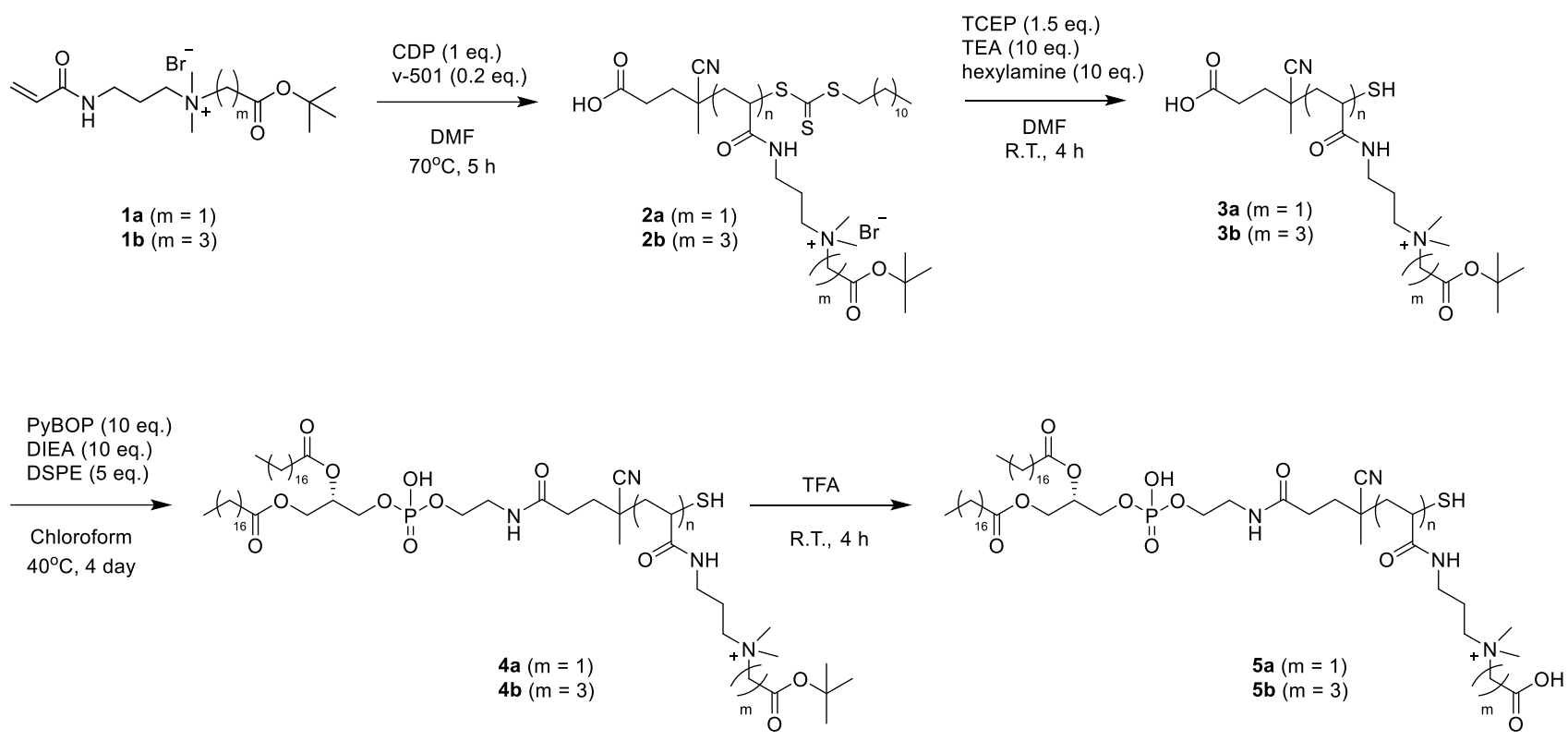

Scheme 1. Synthesis of lipid-modified PCBs. 
Table 1. Characteristics of liposomes with various lipid-modified polymer content.

\begin{tabular}{lccc}
\hline liposome & $\begin{array}{c}\text { mean diameter } \\
(\mathrm{nm})\end{array}$ & PDI & $\zeta$-potential $(\mathrm{mV})$ \\
\hline PCB1 (5\%) & 109 & 0.040 & -12.0 \\
PCB1 (10\%) & 87 & 0.105 & -11.6 \\
PCB1 (15\%) & 80 & 0.117 & -8.6 \\
\hline PCB3 (5\%) & 111 & 0.079 & -10.1 \\
PCB3 (10\%) & 112 & 0.105 & -8.7 \\
PCB3 (15\%) & 96 & 0.057 & -6.7 \\
\hline PEG (5\%) & 106 & 0.045 & -8.8 \\
\hline
\end{tabular}

\section{Blood retention of $\mathrm{PCB}$ liposomes}

We examined the blood retention of PCB-liposomes intravenously injected into mice. As shown in Figure 2, PCB3-liposomes were rapidly cleared from the blood irrespective of the polymer content. In contrast, PCB1-liposomes had comparable blood retention to PEG-liposome, and their blood retention was extended with increased polymer content. PCB1-liposomes with a high polymer content (10\% and $15 \%)$ had a longer blood retention than PEG-liposome. Fluorescence microscopic observation of frozen sections of liver prepared $24 \mathrm{~h}$ after the injection of fluorescence-labeled liposomes showed that the amount of accumulated liposomes in the liver was inversely correlated with their blood retention (Figure 3). PCB3-liposomes had a higher fluorescence than PCB1-liposomes (Figure S3A), indicating the active engulfment of PCB3-liposomes by Kupffer cells. The fluorescence intensity of PCB1-liposomes in the liver was as low as that of PEG-liposome (Figure S3A). These results demonstrated that $\mathrm{PCB} 1$-liposomes have excellent stealthness, which reflects the superior non-fouling nature of PCB1 against blood proteins.[14] 


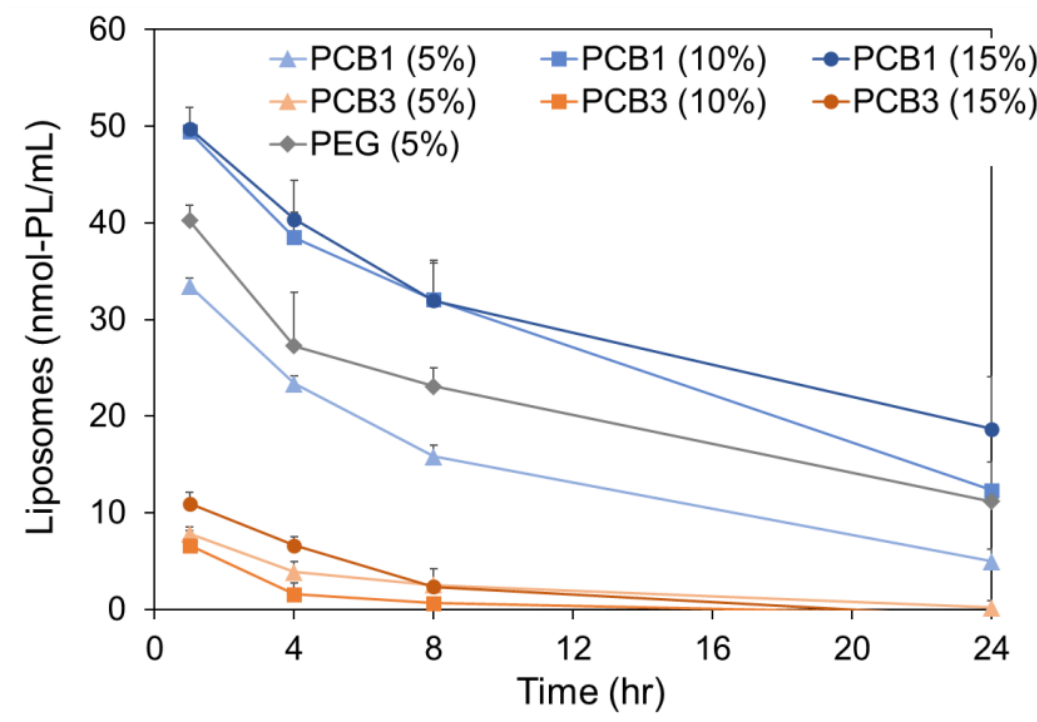

Figure 2. Blood retention of liposomes. Each DiI-labeled liposome (5 $\mu \mathrm{mol} \mathrm{PL} / \mathrm{kg})$ was injected intravenously, then its blood concentration was evaluated. Each value represents the mean \pm S.D. $(n=3)$.

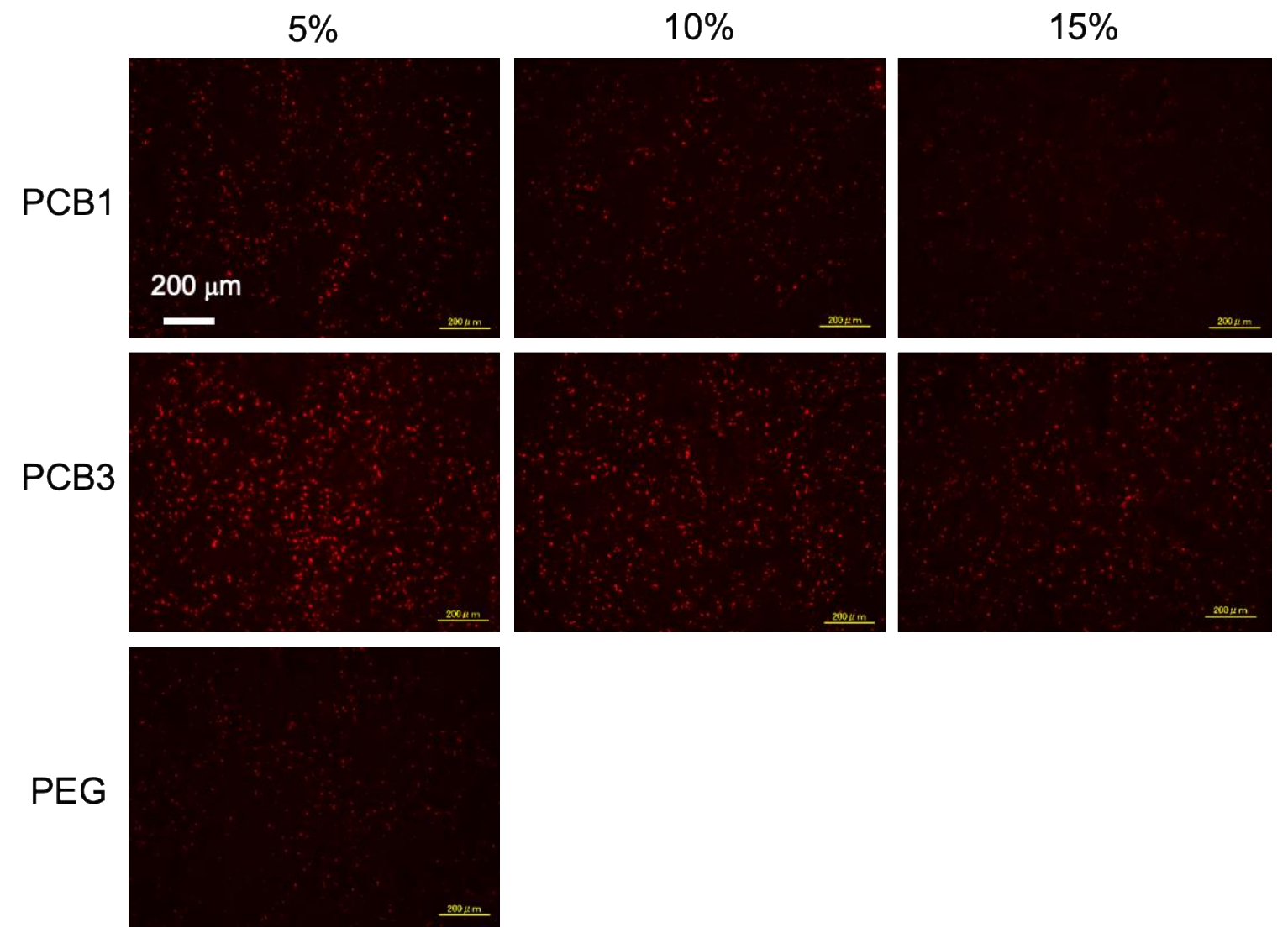

Figure 3. Liver accumulation of liposomes evaluated by fluorescence microscopic observation of frozen sections of liver tissues. At $24 \mathrm{~h}$ after the intravenous injection of DiI-labeled liposomes ( $5 \mu \mathrm{mol} \mathrm{PL} / \mathrm{kg})$, frozen sections (7- $\mu \mathrm{m}$ thickness) were prepared from the liver. The image shown is a representative selection from three independent experiments. 


\section{Induction of antibodies against PCBs}

We examined the induction of IgM and IgG against PCBs by PCB-liposomes. Figure 4A, B shows the results of anti-PEG antibodies production with PEG-liposome as a control. The production of anti-PEG IgG was negligible at all days tested as previously reported;[18] however, anti-PEG IgMs were detected at day 3 and reached a maximum at day 5 , followed by a gradual reduction until day 14 . This time-profile of the amount of IgM in the serum is in line with our previous report.[4] The production of IgMs to PCB1 and PCB3 had a similar time profile to that of anti-PEG IgMs (Figure 4C, E), reaching a maximum at day 5. The dose of PCB-liposomes affected the amount of anti-PCB IgMs produced. Doses up to $0.1 \mu \mathrm{mol}$ PL $/ \mathrm{kg}$ increased anti-PCB IgMs and higher doses reduced anti-PCB IgMs, typical of immunological tolerance at high doses. [4] The critical dose at which IgM production reached a maximum was comparable to that of PEGylated liposomes $(0.01-0.1 \mu \mathrm{mol}$ PL/kg).[4] IgGs specific for both PCBs were not detected at day 14 (Figure 4D, F). 

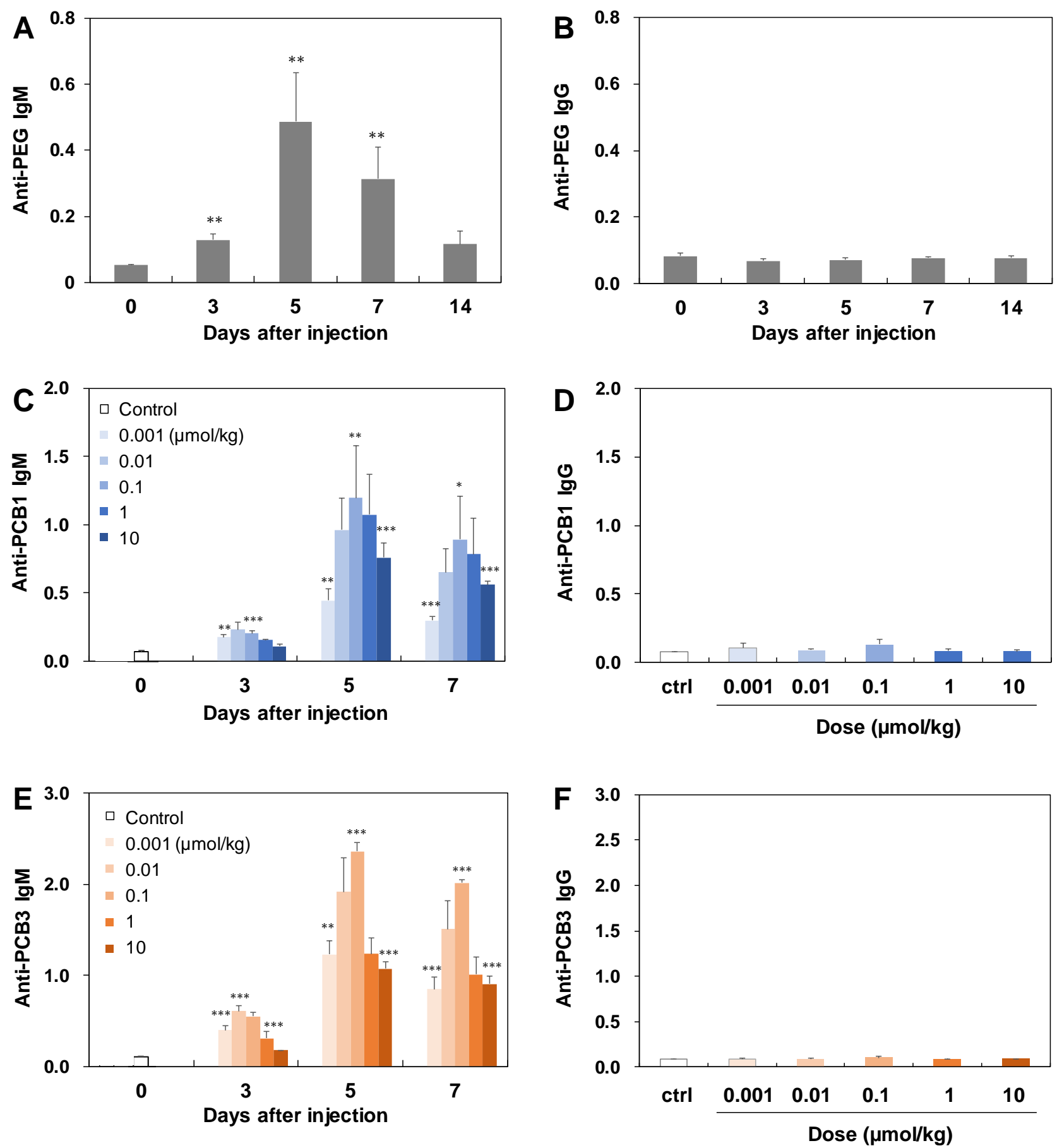

Figure 4. Induction of IgM and IgG against liposomes modified with PEG (A, B), PCB1 (C, D), or PCB3 (E, F). Each liposome (5\% PEG, 10\% PCBs) was intravenously administrated at various doses (PCBs: 0.001-10 $\mu \mathrm{mol}$ PL/kg, PEG: $0.01 \mu \mathrm{mol} \mathrm{PL} / \mathrm{kg}$ ). Then the serum was collected on each day [IgG detection against PCBs was performed at day $14(\mathrm{D}, \mathrm{F})]$. IgM and IgG against each polymer was detected by ELISA. Each value represents the mean \pm S.D. $(n=3)$. P values apply to differences between the control and treated groups. $* \mathrm{P}<$ $0.05, * * \mathrm{P}<0.01, * * * \mathrm{P}<0.005$. 


\section{Specificity of anti-PCB IgMs}

We examined the binding specificity of IgMs induced by each PCB. Here, we used an in vitro system to induce anti-PCB IgMs similar to the method we previously reported for the induction of anti-PEG IgMs.[19] Briefly, each PCB-liposome was added to mouse splenocytes cultured in well plates $\left(5 \times 10^{6} \mathrm{cell} / \mathrm{s} / \mathrm{mL} / \mathrm{well}\right)$. After 5 days of induction, the culture supernatant including IgMs was applied to an ELISA plate immobilized with each PCB to investigate the specificity of IgMs. As shown in Figure 5, IgMs produced by each PCB preferentially bound to its target PCB. IgMs induced by PCB1-liposome had less specificity to its target than those induced by PCB3-liposome.

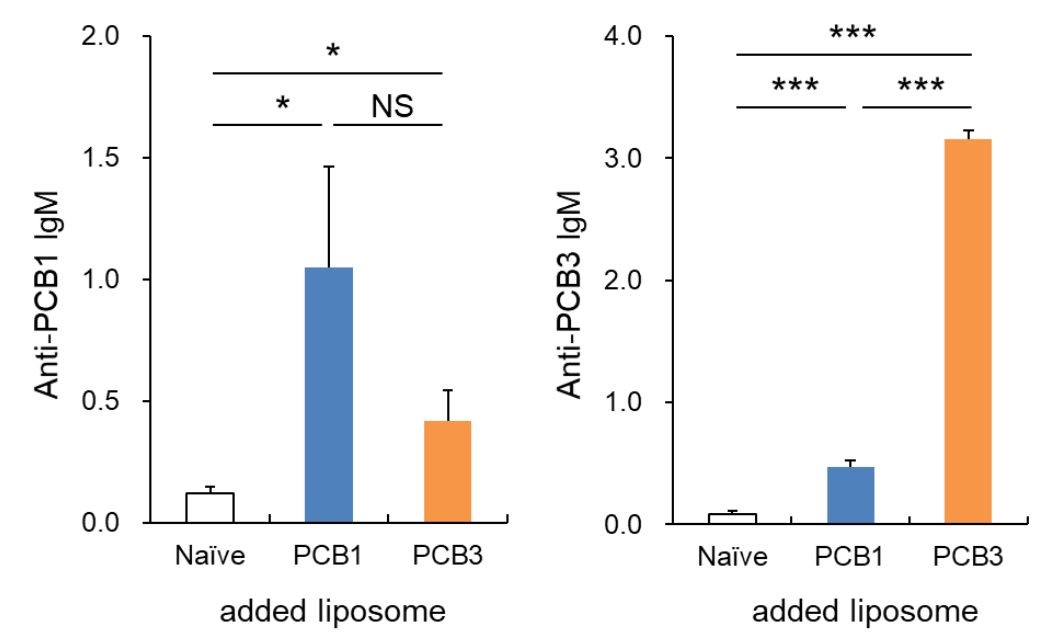

Figure 5. Cross-reactivity of IgMs induced by each PCB-liposome in vitro. Each $10 \%$ PCB-liposome (1 pmol $\mathrm{PL} / \mathrm{mL})$ was applied to splenocytes $\left(5 \times 10^{6} \mathrm{cell} \mathrm{s} / \mathrm{mL}\right)$. After 5 days of induction, the binding specificity of IgM included in the culture supernatant was evaluated by ELISA. P values apply to differences between the naïve and applied groups. $* \mathrm{P}<0.05, * * * \mathrm{P}<0.005$.

\section{ABC phenomenon of PCB-liposomes}

The ABC phenomenon of each PCB-liposome was evaluated based on our standard protocol. Briefly, mice received an initial injection of an optimum dose $(0.1 \mu \mathrm{mol} \mathrm{PL} / \mathrm{kg})$ of each PCB-liposome determined from Figure 4. After 5 days, when the blood concentration of anti-PCB IgMs was maximal, a second injection of fluorescence-labeled PCB-liposomes was performed. The serum concentrations of each liposome $4 \mathrm{~h}$ after the first and the second injections are summarized in Figure 6A. Both PCB1 and PCB3-liposomes were almost completely cleared from the blood similar to PEG-liposome, demonstrating the occurrence of ABC phenomena for PCB-liposomes. Figure 6B shows fluorescence images of liver sections $4 \mathrm{~h}$ after each injection. A group treated with PCB1-liposomes had stronger fluorescence after the second injection compared with the first injection similar to that of PEG-liposome (Figure S3B). This is clear evidence that anti-PCB IgMs induced by the first injection opsonized PCB-liposomes to be rapidly cleared from the blood via engulfment by Kupffer cells. 

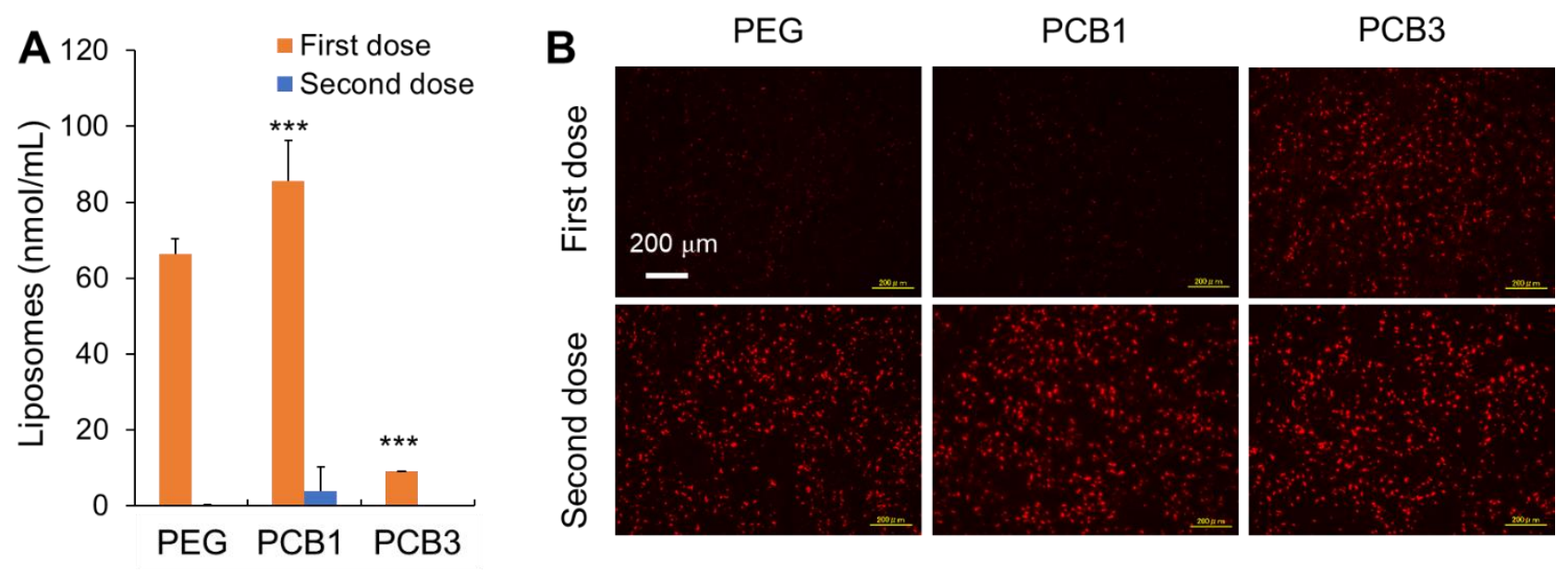

Figure 6. $\mathrm{ABC}$ phenomenon toward each liposome (A) and the liver accumulation of each liposome $4 \mathrm{~h}$ after the first (day 0) and second injection (day 5) of each liposome (B). For the first dose group, DiI-labeled liposomes (5\% PEG, 10\% PCBs) were administered at a dose of $5 \mu \mathrm{mol} \mathrm{PL} / \mathrm{kg}$. For the second dose group, 5 days after the first injection of liposomes at a dose of $0.1 \mu \mathrm{mol} \mathrm{PL} / \mathrm{kg}$ (PCB-liposomes) or $0.01 \mu \mathrm{mol} \mathrm{PL} / \mathrm{kg}$ (PEG-liposome), a second injection of the same liposome (DiI-labeled) was conducted at a dose of $5 \mu \mathrm{mol}$ $\mathrm{PL} / \mathrm{kg}$. Four $\mathrm{h}$ after each injection, the blood and liver were collected to examine the presence of liposomes. In panel A, each value represents the mean \pm S.D. $(n=3)$. P values apply to differences between non-treated and treated groups. ${ }^{* * *} \mathrm{P}<0.005$. In panel $\mathrm{B}$, frozen liver sections $(7-\mu \mathrm{m}$ thickness) were prepared from the collected liver. The image is a representative selection from three independent experiments.

\section{Discussion}

We examined the blood retention and antigenicity of PCB-liposomes. We found that PCB3-liposomes had a short blood retention, whereas PCB1-liposomes exhibited an extended blood circulation, which was better than PEG-liposome at the high PCB1 contents (Figure 2). The superior blood retention of PCB1-liposomes reflected its excellent non-fouling nature toward blood proteins.[13][14] However, PCB1- as well as PCB3liposomes elicited specific IgMs, similar to that observed for PEG-liposome. Subsequently, the ABC phenomenon was observed for PCB1- and PCB3-liposomes: a second dose of injected liposomes was rapidly cleared from the blood related to opsonization by specific IgMs elicited by the first injection (Figure 6). The amount of IgMs specific to the target PCB was dependent on the dose of the PCB-liposomes injected (Figure 4). The amount of IgMs reached a maximum at a dose of $0.1 \mu \mathrm{mol} \mathrm{PL} / \mathrm{kg}$, whereas higher doses reduced the amount of IgMs. This is a phenomenon typical of using high doses for immunological tolerance, and is a consequence of anergic responses of B cells that experience continuous stimulation by antigens.[20]

The current results showing IgM production against PCBs is in conflict with results from a previous report, in which IgM toward methacrylate-type PCB2-liposome was not detected.[9] The following reasons might explain the discrepancy between these results. (1) Difference in PCB structures. Because we used an 
acrylamide-type PCB1, the structure of the PCB might differ in its ability to induce antibodies. (2) Difference in PCB terminal groups. A bromo group remained on the terminus of the PCB in the previous study, [9] whereas a thiol group existed on the terminus in the current study. A terminal thiol group on PEG was reported to enhance anti-PEG IgM production to a PEGylated emulsion.[17] Thus, a terminal thiol group on PCBs might enhance the antigenicity of PCB-liposomes. (3) Different doses and study animals. Mice were used in the current study, whereas rats were used in the previous report.[9] We previously found rats showed immunological tolerance to PEG-liposomes at a dose at least one order of magnitude lower than mice.[4] The dose of PCB2-liposome based on the number of PCB2 chains, was in the $\mu$ mol-chain $/ \mathrm{kg}$ range in the previous report[9][26]. This is an dose equivalent to that used previously by our group, where almost no anti-PEG IgM was produced in rats due to immunological tolerance.[4][7]

The current results would not be in conflict with studies reporting acrylamide-type PCB1 conjugated with proteins did not induce anti-PCB1 antibodies.[10][11] For polymeric compounds with a repeated structure, such as PEG and PCBs, to induce antibody production, B cell receptors (BCRs) on the B cell surface should be crosslinked to induce signaling that activates the B cell.[21] The PEGylated liposome is large enough (approximately $100 \mathrm{~nm}$ ) to crosslink multiple BCRs. In contrast, PEGylated nanoparticles with small sizes (approximately $<30 \mathrm{~nm}$ ) did not induce anti-PEG IgM production.[22] Because proteins are usually small, protein-polymer conjugates may be less potent at inducing anti-polymer antibodies compared with polymermodified liposomes.

Of note, an aliquot of splenocytes $\left(5 \times 10^{6}\right)$ from approximately $10^{8}$ mouse splenocytes induced antiPCB IgMs in vitro (Figure 5). Because approximately 50\% of splenocytes are B cells[23], this suggests the existence of B cell clones that bind to PCB1 with an affinity high enough to induce anti-PCB1 IgMs. The generated IgMs specifically bound to each target PCB, indicating the IgMs specifically recognized the different zwitterion structures of PCB1 and PCB3. Anti-PCB1 IgMs were less selective than anti-PCB3 IgMs (Figure 5) suggesting the lower affinity of anti-PCB1 IgMs compared with anti-PCB3 IgMs to their target PCBs. The zwitterionic group of PCB1 is less charged than that of PCB3 due to interplay between the cationic and anionic groups.[15] This uniquely charged zwitterionic group of PCB1 was speculated to have weak interactions with proteins;[16] therefore, even BCRs, which have diverse structures to recognize any pathogens, bind weakly to the zwitterion of PCB1.

\section{Conclusion}

We examined the blood retention and antigenicity of liposomes modified with acrylamide-type PCB1 or PCB3. PCB3-liposomes had a short blood retention, whereas PCB1-liposomes demonstrated an extended blood retention, which was better than PEG-liposome when the PCB1 content was high. This study indicates the potential of PCB1 as an alternative stealth polymer. However, PCB1 - as well as PCB3-liposomes induced specific IgM, which was suppressed at high doses of PCB-liposomes due to immunological tolerance. After the induction of specific IgMs by the first injection of an optimal dose, PCB-liposomes in the second dose were rapidly cleared from the blood due to liver accumulation. The present study shows the importance of examining the effect of dose on the antigenicity of stealth polymers. 


\section{Acknowledgement}

We thank Dr. Shin-ichi Yusa for his advice in polymer synthesis. This work is supported by The Japan Society for the Promotion of Science, a Grant-in-Aid for Fund for the Promotion of Joint International Research (Fostering Joint International Research (B) (19KK0279)).

\section{References and note}

[1] A.S. Abu Lila, H. Kiwada, T. Ishida, The accelerated blood clearance (ABC) phenomenon: Clinical challenge and approaches to manage, J. Control. Release. 172 (2013) 38-47. https://doi.org/10.1016/j.jconrel.2013.07.026.

[2] Q. Yang, S.K. Lai, Anti-PEG immunity: Emergence, characteristics, and unaddressed questions, Wiley Interdiscip. Rev. Nanomedicine Nanobiotechnology. 7 (2015) 655-677. https://doi.org/10.1002/wnan.1339.

[3] P. Zhang, F. Sun, S. Liu, S. Jiang, Anti-PEG antibodies in the clinic: Current issues and beyond PEGylation, J. Control. Release. 244 (2016) 184-193. https://doi.org/10.1016/j.jconrel.2016.06.040.

[4] M. Ichihara, T. Shimizu, A. Imoto, Y. Hashiguchi, Y. Uehara, T. Ishida, H. Kiwada, Anti-PEG IgM response against PEGylated liposomes in mice and rats, Pharmaceutics. 3 (2011) 1-11. https://doi.org/10.3390/pharmaceutics3010001.

[5] T. Suzuki, M. Ichihara, K. Hyodo, E. Yamamoto, T. Ishida, H. Kiwada, H. Kikuchi, H. Ishihara, Influence of dose and animal species on accelerated blood clearance of PEGylated liposomal doxorubicin, Int. J. Pharm. 476 (2014) 205-212. https://doi.org/10.1016/j.ijpharm.2014.09.047.

[6] T. Shimizu, Y. Mima, Y. Hashimoto, M. Ukawa, H. Ando, H. Kiwada, T. Ishida, Anti-PEG IgM and complement system are required for the association of second doses of PEGylated liposomes with splenic marginal zone B cells, Immunobiology. 220 (2015) 1151-1160. https://doi.org/10.1016/j.imbio.2015.06.005.

[7] T. Ishida, M. Harada, Y.W. Xin, M. Ichihara, K. Irimura, H. Kiwada, Accelerated blood clearance of PEGylated liposomes following preceding liposome injection: Effects of lipid dose and PEG surfacedensity and chain length of the first-dose liposomes, J. Control. Release. 105 (2005) 305-317. https://doi.org/10.1016/j.jconrel.2005.04.003.

[8] Q. Yang, T.M. Jacobs, J.D. McCallen, D.T. Moore, J.T. Huckaby, J.N. Edelstein, S.K. Lai, Analysis of pre-existing IgG and IgM antibodies against polyethylene glycol (PEG) in the general population, Anal. Chem. 88 (2016) 11804-11812. https://doi.org/10.1021/acs.analchem.6b03437.

[9] Y. Li, R. Liu, Y. Shi, Z. Zhang, X. Zhang, Zwitterionic poly(carboxybetaine)-based cationic liposomes for effective delivery of small interfering RNA therapeutics without accelerated blood clearance phenomenon, Theranostics. 5 (2015) 583-596. https://doi.org/10.7150/thno.11234.

[10] P. Zhang, F. Sun, C. Tsao, S. Liu, P. Jain, A. Sinclair, H.C. Hung, T. Bai, K. Wu, S. Jiang, Zwitterionic gel encapsulation promotes protein stability, enhances pharmacokinetics, and reduces immunogenicity, Proc. Natl. Acad. Sci. U. S. A. 112 (2015) 12046-12051. 
https://doi.org/10.1073/pnas.1512465112.

[11] B. Li, Z. Yuan, H.C. Hung, J. Ma, P. Jain, C. Tsao, J. Xie, P. Zhang, X. Lin, K. Wu, S. Jiang, Revealing the Immunogenic Risk of Polymers, Angew. Chemie - Int. Ed. 57 (2018) 13873-13876. https://doi.org/10.1002/anie.201808615.

[12] B. Li, P. Jain, J. Ma, J.K. Smith, Z. Yuan, H.C. Hung, Y. He, X. Lin, K. Wu, J. Pfaendtner, S. Jiang, Trimethylamine N-oxide-derived zwitterionic polymers: A new class of ultralow fouling bioinspired materials, Sci. Adv. 5 (2019). https://doi.org/10.1126/sciadv.aaw9562.

[13] Z. Zhang, H. Vaisocherová, G. Cheng, W. Yang, H. Xue, S. Jiang, Nonfouling behavior of polycarboxybetaine-grafted surfaces: Structural and environmental effects, Biomacromolecules. 9 (2008) 2686-2692. https://doi.org/10.1021/bm800407r.

[14] H. Vaisocherová, Z. Zhang, W. Yang, Z. Cao, G. Cheng, A.D. Taylor, M. Piliarik, J. Homola, S. Jiang, Functionalizable surface platform with reduced nonspecific protein adsorption from full blood plasmaMaterial selection and protein immobilization optimization, Biosens. Bioelectron. 24 (2009) 19241930. https://doi.org/10.1016/j.bios.2008.09.035.

[15] Q. Shao, S. Jiang, Effect of carbon spacer length on zwitterionic carboxybetaines, J. Phys. Chem. B. 117 (2013) 1357-1366. https://doi.org/10.1021/jp3094534.

[16] Q. Shao, S. Jiang, Influence of charged groups on the properties of zwitterionic moieties: A molecular simulation study, J. Phys. Chem. B. 118 (2014) 7630-7637. https://doi.org/10.1021/jp5027114.

[17] C. Wang, X. Cheng, Y. Sui, X. Luo, G. Jiang, Y. Wang, Z. Huang, Z. She, Y. Deng, A noticeable phenomenon: Thiol terminal PEG enhances the immunogenicity of PEGylated emulsions injected intravenously or subcutaneously into rats, Eur. J. Pharm. Biopharm. 85 (2013) 744-751. https://doi.org/10.1016/j.ejpb.2013.10.002.

[18] T. Ishida, X.Y. Wang, T. Shimizu, K. Nawata, H. Kiwada, PEGylated liposomes elicit an anti-PEG IgM response in a T cell-independent manner, J. Control. Release. 122 (2007) 349-355. https://doi.org/10.1016/j.jconrel.2007.05.015.

[19] A.S.A. Lila, M. Ichihara, T. Shimizu, T. Ishida, H. Kiwada, Ex-vivo/in-vitro anti-polyethylene glycol (PEG) immunoglobulin M production from murine splenic B cells stimulated by pegylated liposome, Biol. Pharm. Bull. 36 (2013) 1842-1848. https://doi.org/10.1248/bpb.b13-00562.

[20] S. Elizabeth Franks, J.C. Cambier, Putting on the brakes: Regulatory kinases and phosphatases maintaining B cell anergy, Front. Immunol. 9 (2018) 1-7. https://doi.org/10.3389/fimmu.2018.00665.

[21] Q. Vos, A. Lees, Z.Q. Wu, C.M. Snapper, J.J. Mond, B-cell activation by T-cell-independent type 2 antigens as an integral part of the humoral immune response to pathogenic microorganisms, Immunol. Rev. 176 (2000) 154-170. https://doi.org/10.1034/j.1600-065X.2000.00607.x.

[22] H. Koide, T. Asai, K. Hatanaka, T. Urakami, T. Ishii, E. Kenjo, M. Nishihara, M. Yokoyama, T. Ishida, H. Kiwada, N. Oku, Particle size-dependent triggering of accelerated blood clearance phenomenon, Int. J. Pharm. 362 (2008) 197-200. https://doi.org/10.1016/j.ijpharm.2008.06.004.

[23] A. Pellegrini, N. Guiñazú, M.P. Aoki, I.C. Calero, E.A. Carrera-Silva, N. Girones, M. Fresno, S. Gea, Spleen B cells from BALB/c are more prone to activation than spleen B cells from C57BL/6 mice 
during a secondary immune response to cruzipain, Int. Immunol. 19 (2007) 1395-1402. https://doi.org/10.1093/intimm/dxm107.

[24] In reference 9 , dose of siRNA was $1 \mathrm{mg}$-siRNA/ $\mathrm{kg}$. Considering $\mathrm{N} / \mathrm{P}$ ratio $=5$ and a liposome composition (cationic lipid/PCB2-lipid $=1 / 0.2$ ), this dose can be converted to dose in PCB as $3 \mu \mathrm{mol}-$ $\mathrm{PCB}$ chain $/ \mathrm{kg}$. 


\section{Graphical abstract}

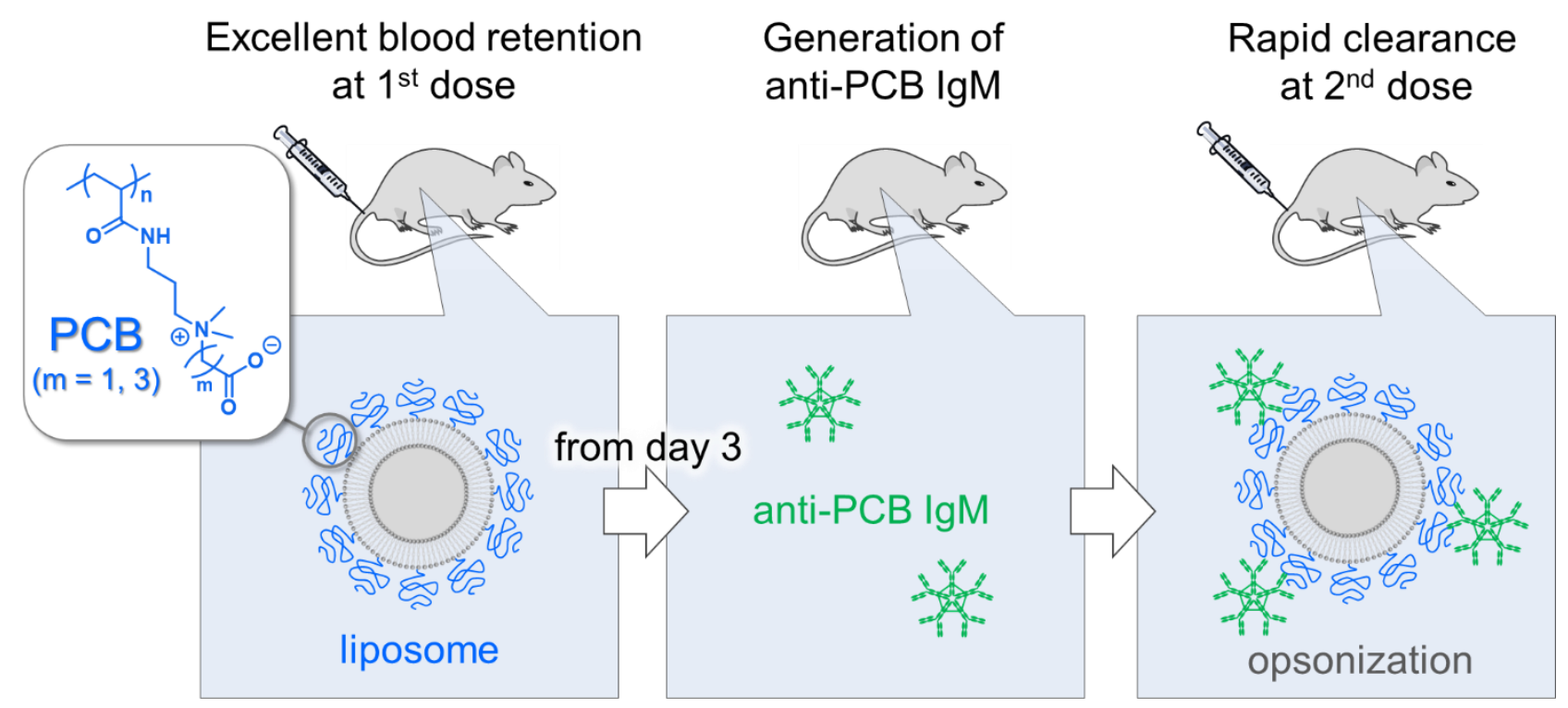




\section{Supplementary information}

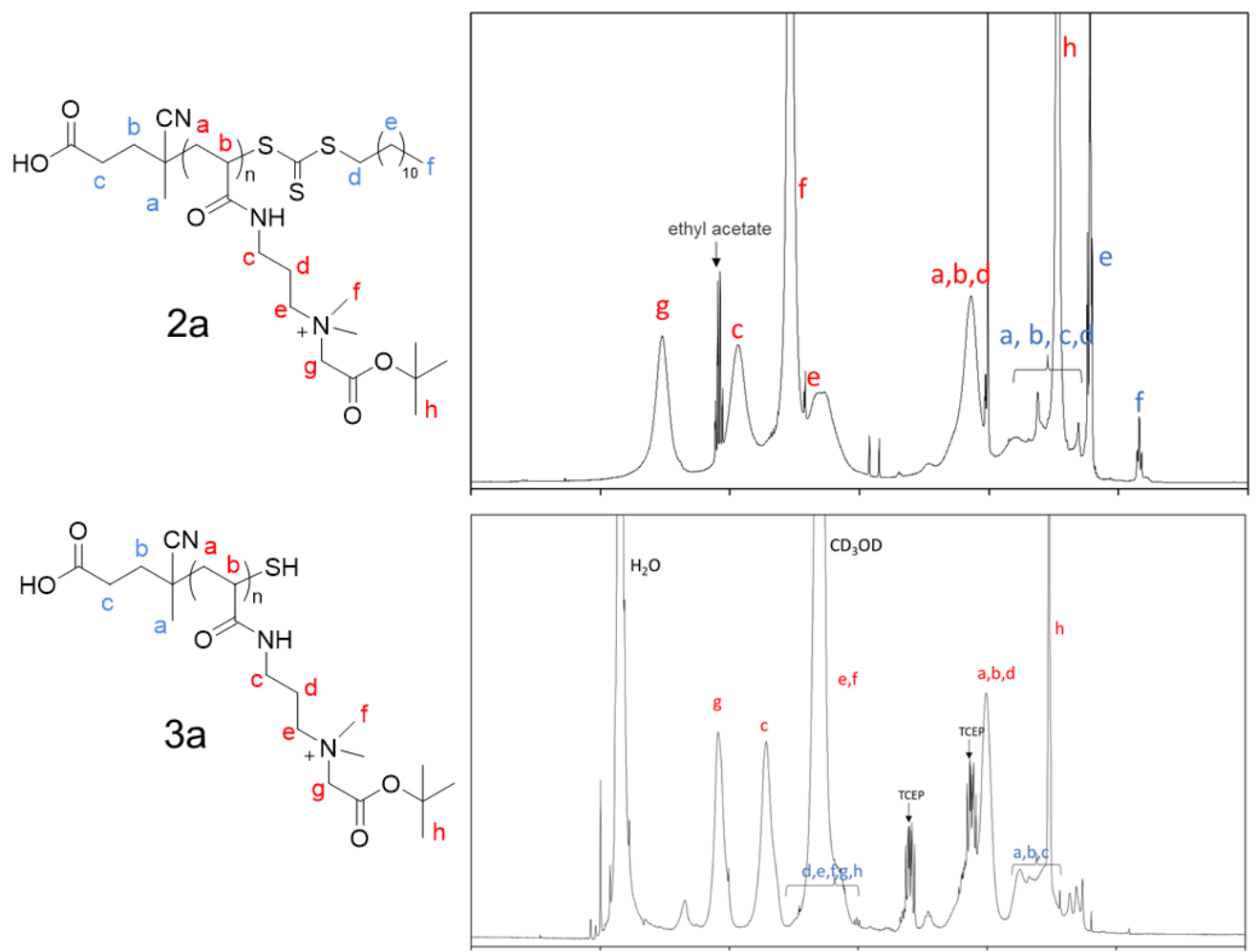

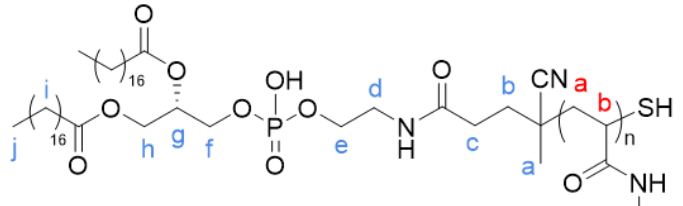

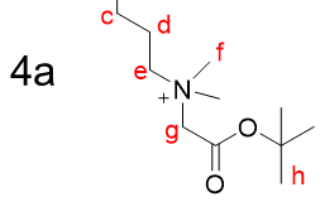

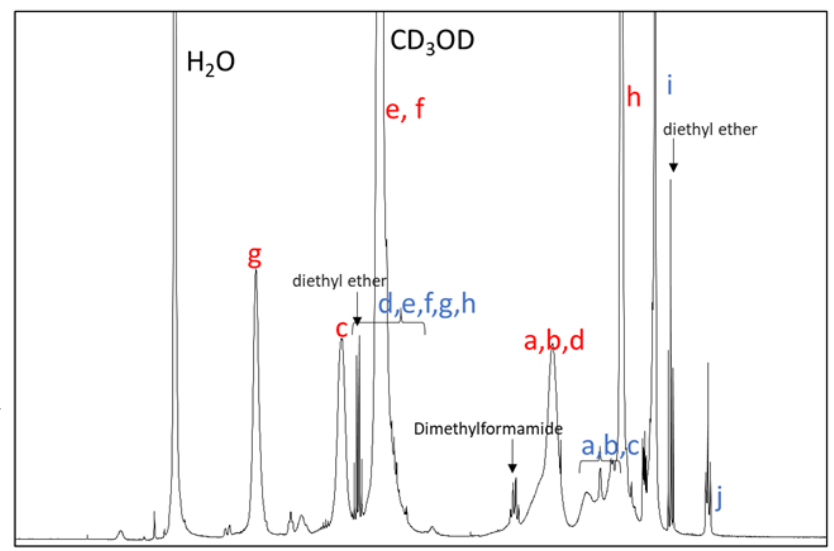

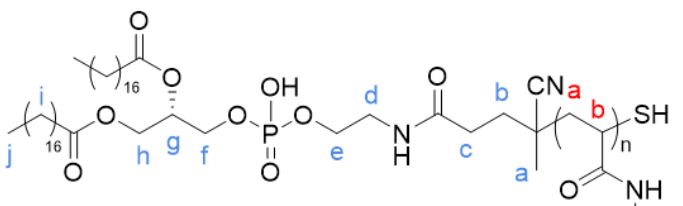

$$
\begin{aligned}
& 5 a \\
& \left.\right|_{0} ^{c} \mathrm{OH}
\end{aligned}
$$

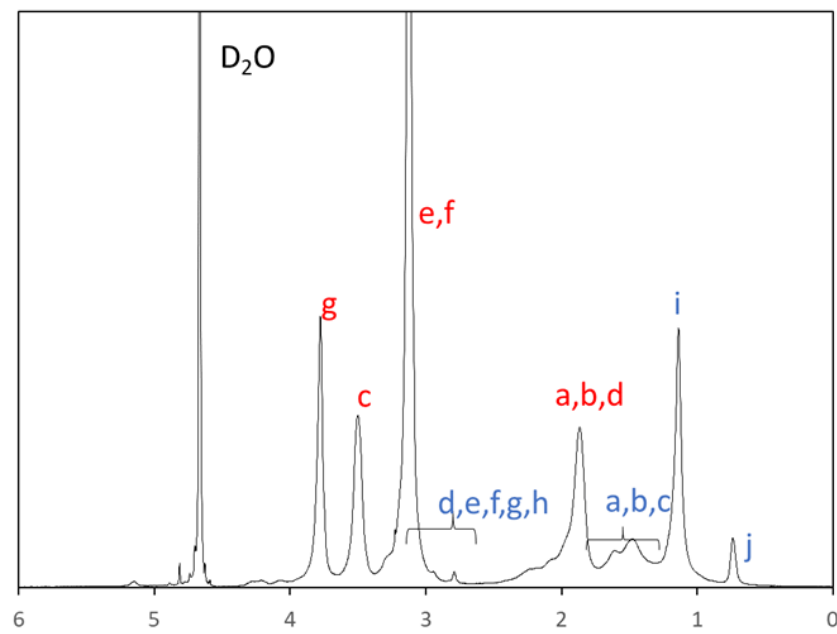

Figure S1. ${ }^{1} \mathrm{H}$ spectra of compound $\mathbf{2 a - 5 a}(300 \mathrm{MHz}, 298 \mathrm{~K})$. Solvents were $\mathrm{CDCl}_{3}(\mathbf{2 a}, \mathbf{3 a}), \mathrm{CD}_{3} \mathrm{OD}(\mathbf{4 a})$, and $\mathrm{D}_{2} \mathrm{O}(\mathbf{5 a})$, respectively. 


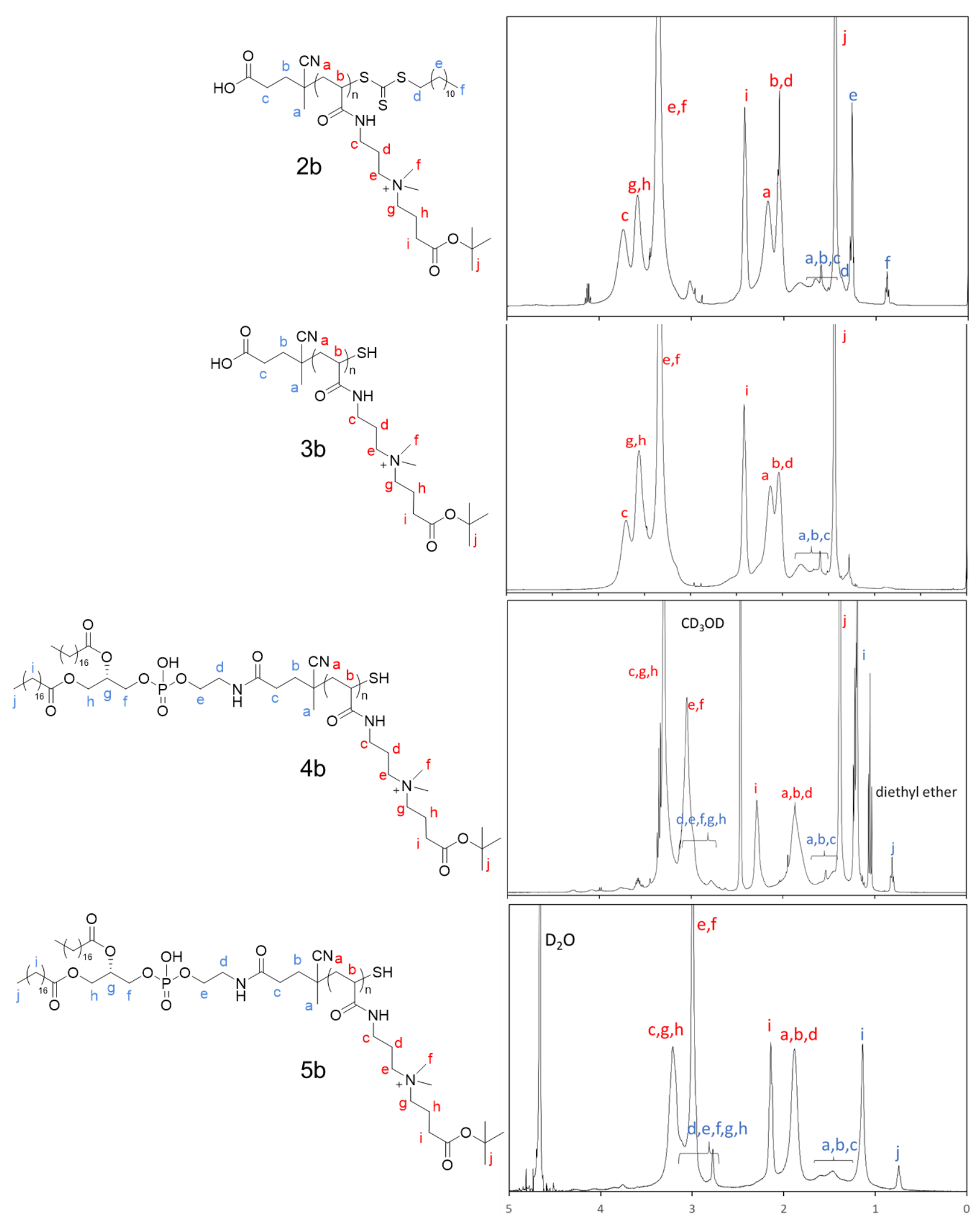

Figure S2. ${ }^{1} \mathrm{H}$ spectra of compound $\mathbf{2 b - 5 b}(300 \mathrm{MHz}, 298 \mathrm{~K})$. Solvents were $\mathrm{CDCl}_{3}(\mathbf{2 b}, \mathbf{3 b}), \mathrm{CD}_{3} \mathrm{OD}(\mathbf{4 b})$, and $\mathrm{D}_{2} \mathrm{O}(\mathbf{5 b})$, respectively. 

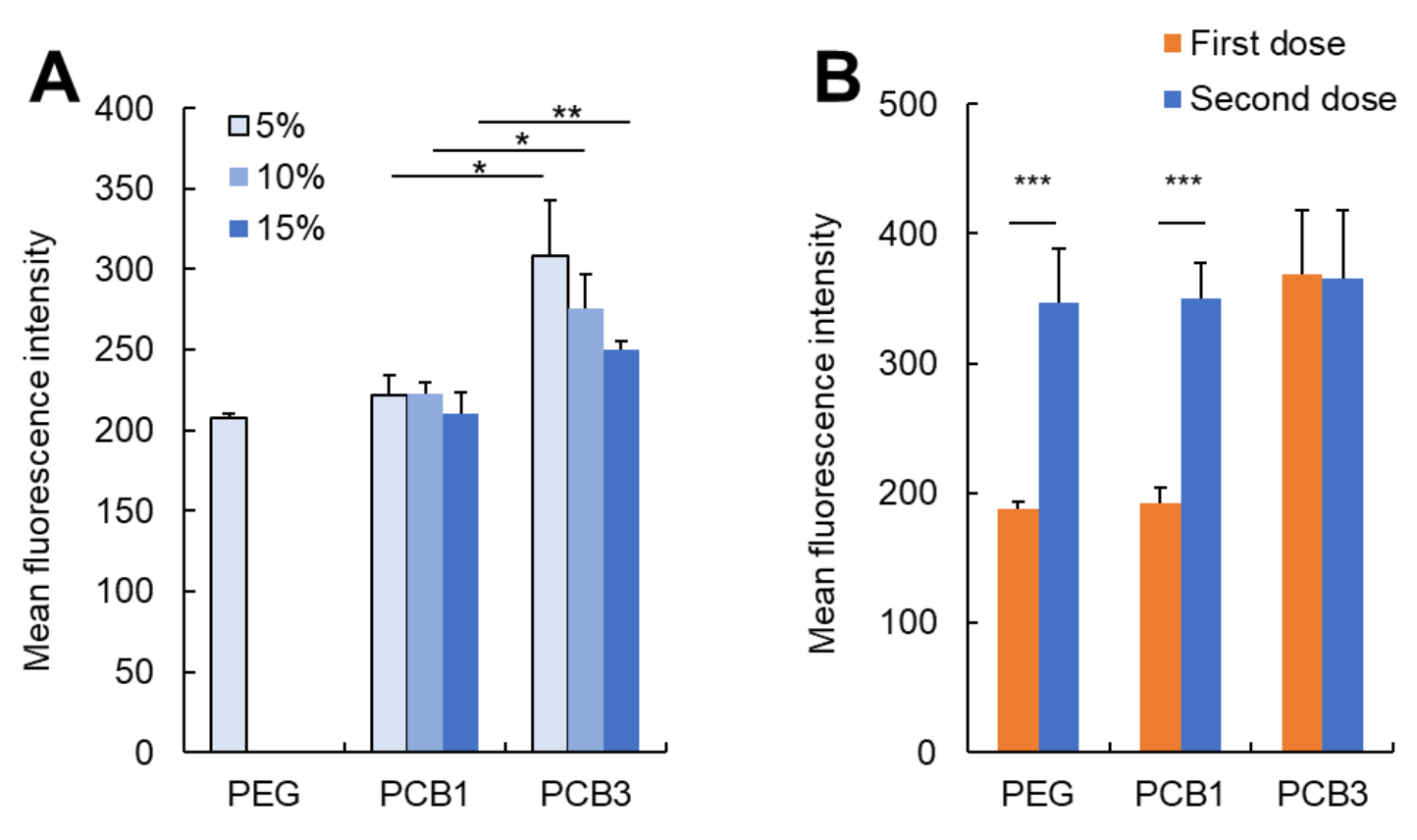

Figure S3. Quantification of fluorescence intensity of images of liver tissue frozen sections. Summary of the result of Figure 3 (images of three sections per group) (A) and Figure 6B (images of twelve sections per groups) (B). $* \mathrm{P}<0.05, * * * \mathrm{P}<0.005$. 